\title{
Queijo de coalho artesanal: fonte alternativa de peptídeos antimicrobianos
} Artisanal "coalho" cheese: alternative source of antimicrobial peptides

\author{
Meire dos Santos Falcão de Lima ${ }^{1,2}$, Roberto Afonso da Silva', José Luiz de Lima Filho', Ana Lúcia Figueiredo Porto², \\ Maria Taciana Holanda Cavalcanti ${ }^{2 \star}$ \footnotetext{
Saúde, Recife/PE - Brasil

${ }^{2}$ Universidade Federal Rural de Pernambuco (UFRPE), Departamento de Morfologia e Fisiologia Animal, Laboratório de Tecnologia de Bioativos, Recife/PE - Brasil
} \\ 1 Universidade Federal de Pernambuco (UFPE), Laboratório de Imunopatologia Keizo Asami, Programa de Pós-graduação em Biologia Aplicada à
}

\section{*Corresponding Author}

Maria Taciana Holanda Cavalcanti, Universidade Federal Rural de Pernambuco (UFRPE), Departamento de Morfologia e Fisiologia Animal, Rua Dom Manoel de Medeiros, s/n, Dois Irmãos, CEP: 52171-900, Recife/PE - Brasil, e-mail: mtcvsoares@yahoo.com.br

Cite as: Artisanal "coalho" cheese: alternative source of antimicrobial peptides. Braz. J. Food Technol., v. 20, e2016193, 2017.

\section{Resumo}

O objetivo da pesquisa foi extrair, obter o perfil peptídico e avaliar a atividade antimicrobiana do extrato peptídico bruto de duas amostras de queijo de Coalho artesanal produzidos no município de Venturosa, localizado no Agreste de Pernambuco - Brasil. Nas eletroforeses realizadas, foram evidenciadas de 12 a 15 bandas. Na análise por espectrometria de massa, foram identificados 24 fragmentos peptídeos. O extrato peptídico bruto apresentou atividade antimicrobiana diante dos microrganismos Enterococcus faecalis ATCC 6057, Bacillus subtilis ATCC 6633, Escherichia coli ATCC 25922 e Pseudomonas aeruginosa ATCC 27853 na concentração de $225 \mathrm{mg} / \mathrm{mL}$. Os presentes resultados sugerem que em aproximadamente $5 \mathrm{~g}$ do queijo são encontrados peptídeos capazes de inibir o crescimento dos microrganismos patogênicos testados. Sendo assim, pode-se indicar o caráter funcional do queijo de Coalho.

Palavras-chave: Eletroforese SDS-PAGE; Espectrometria por MALDI-ToF; Atividade antimicrobiana; Peptídeos bioativos.

\section{Abstract}

The aim of this research was to extract the crude peptide extracts from two samples of artisanal "Coalho" cheese produced in the city of Venturosa in the drylands of the State of Pernambuco - Brazil, and evaluate their peptide profile and antimicrobial activity. Electrophoresis showed evidence of 12 to 15 bands and mass spectrometry identified 24 peptide fragments. Furthermore, the crude extract presented antimicrobial activity against Enterococcus faecalis ATCC 6057, Bacillus subtilis ATCC 6633, Escherichia coli ATCC 25922 and Pseudomonas aeruginosa ATCC 27853 at a concentration of $225 \mathrm{mg} / \mathrm{mL}$. The present results suggest that peptides capable of inhibiting the growth of the pathogenic microorganisms tested can be found in approximately $5 \mathrm{~g}$ of the cheese. Thus "Coalho" cheese can be indicated for its functional character.

Keywords: SDS-PAGE electrophoresis; MALDI-ToF spectrometry; Antimicrobial activity; Bioactive peptides. 


\section{Introdução}

Na maioria dos estados brasileiros existe a tradição do consumo de produtos artesanais, como queijos, cujo consumo, em geral, está ligado à cultura local. A qualidade dos queijos artesanais está relacionada com o modo de produção e as características do leite (sua composição físico-química está relacionada com a raça do rebanho, alimentação, clima etc.), assim, esses produtos refletem o território em que são fabricados. Sendo assim, o consumo desses produtos significa proteger a singularidade de seu ambiente histórico e cultural (ZAFFARI et al., 2007; PAQUEREAU et al., 2016).

Queijo de coalho é um alimento típico brasileiro, que é produzido a partir de leite cru ou pasteurizado na Região Nordeste há mais de 150 anos. As principais características desse queijo são o seu sabor levemente salgado e ácido e sua resistência ao calor sem derreter, o que permite a preparação do "popular" queijo assado. O queijo de Coalho é produzido principalmente nos estados do nordeste do Brasil: Pernambuco, Ceará, Rio Grande do Norte e Paraíba. Esse queijo tem uma participação considerável na economia, sendo significativo na renda dos fornecedores de leite, especialmente daqueles que não têm acesso a unidades de processamento de leite (QUEIROGA et al., 2013; SILVA et al., 2012; PAQUEREAU et al., 2016).

O número crescente de produtos alimentícios e a tendência atual de consumo de produtos naturais vêm aumentando o interesse dos meios científicos no estudo da composição e características funcionais desses alimentos (MILLS et al., 2011). Os derivados lácteos detêm uma quota importante neste mercado, pois o seu processo de fabricação envolve adição de bactérias ácido lácticas (BAL). Essas bactérias têm sido estudadas quanto a suas características probióticas e produtoras de metabólitos secundários, como as bacteriocinas, associadas com efeitos de promoção da saúde (ALMEIDA JÚNIOR et al., 2015).

Os metabólitos mais importantes do processo bioquímico para o sabor e a textura de diversos tipos de queijos são as proteínas. Os efeitos dessas proteínas sobre a saúde humana podem estar relacionados à proteína intacta, aos aminoácidos da proteína totalmente digerida e aos peptídeos da proteína parcialmente hidrolisada (HERNÁNDEZ-LEDESMA et al., 2014; SILVA et al., 2012).

Proteínas alimentares podem agir como precursores de peptídeos antimicrobianos que iniciam a defesa natural do organismo contra patógenos, logo, podem ser consideradas como componentes fundamentais para o sistema imune. Fragmentos de proteínas conhecidos pelas suas atividades biológicas são os peptídeos bioativos, que apresentam impactos positivos nas funções orgânicas, podendo promover a saúde. Eles têm sido isolados de produtos lácteos incluindo queijos, iogurtes e leites fermentados. Os peptídeos antimicrobianos provenientes da caseína têm mostrado capacidade de eliminar células-alvo rapidamente e com um amplo espectro de atividade (LIRA et al., 2010; LÓPEZ-EXPÓSITO; RECIO, 2006).

A pesquisa por peptídeos bioativos em produtos lácteos regionais, como o queijo de Coalho, é importante para a valorização do produto. Assim, esta pesquisa teve por objetivo a extração de peptídeos solúveis em água a partir do queijo de Coalho artesanal, produzido no município de Venturosa/PE, e a avaliação sua da atividade antimicrobiana.

\section{Material e métodos}

Duas amostras de queijos de Coalho artesanais de aproximadamente $1 \mathrm{~kg}$, fabricados com leite cru, foram adquiridas no município de Venturosa/PE, durante os meses de março e julho de 2011. As amostras foram coletadas em sacos plásticos, identificadas e foram mantidas a $10^{\circ} \mathrm{C}$ até o momento das análises (realizadas em triplicata).

Amostras de cada queijo de Coalho (40 g) foram homogeneizadas com água na proporção 1:2 (p/v) a 101 xg por 5 minutos em homogeneizador (Nissei AM-8). Em seguida, foram centrifugadas três vezes a $8000 \mathrm{~g}$ por $30 \mathrm{~min}$, a $4{ }^{\circ} \mathrm{C}$. Depois da recuperação de $75 \%$ do volume utilizado, o sobrenadante final foi filtrado em papel de filtro quantitativo (Whatman $n^{\circ} 40$ ), foi liofilizado, denominado extrato peptídico solúvel bruto, e armazenado a $-20{ }^{\circ} \mathrm{C}$ até ser utilizado nas etapas seguintes.

A quantificação proteica foi realizada pelo método de Lowry et al. (1951), utilizando albumina de soro bovina como padrão.

A eletroforese SDS-PAGE foi realizada pelo método descrito por Egito et al. (2006). O volume de extrato peptídico bruto equivalente a $200 \mu \mathrm{g}$ de proteína foi usado como amostra. De acordo com o tamanho das proteínas do leite, foram escolhidos os marcadores de peso molecular (Bio-Rad): lisozima (14,4 kDa), inibidor de tripsina (21,5 kDa), anidrase carbônica (31,0 kDa), ovoalbumina (45,0 kDa), soroalbumina (66,2 kDa), fosforilase b $(97,4 \mathrm{kDa})$.

Para a espectrometria de massas (Maldi-TOF), os peptídeos solúveis em água foram pré-purificados em ponteiras que contêm uma pequena coluna cromatográfica C18 do tipo ZipTip. Em seguida, os peptídeos foram eluídos com $10 \mu \mathrm{L}$ da solução de eluição (50\% acetonitrila contendo 0,1\% ácido trifluoroacético).

Para obtenção do perfil peptídico foi utilizado o sistema Ettan MALDI-TOF-Pro (Amersham Biosciences), equipado com um refletor de campo quadrático e porta de íon cronometrada. A aquisição dos peptídeos foi realizada em modo linear com ionização positiva, rejeição de massa 500 m/z, velocidade de aquisição de 8 disparos/segundo, potencial de aceleração dos íons de 20 kV. Foram adicionados $150 \mu \mathrm{L}$ de ácido trifluoroacético 0,1\% (v/v) no extrato de peptídeos solúveis obtidos após a separação com 
a ponteira Zip Tip C18. Em seguida, $1 \mu \mathrm{L}$ desta solução foi misturado na proporção de 1:1, com a solução matriz (ácido -ciano-4-hidroxi-cinâmico em 50\% de acetonitrila (v/v) contendo 0,1\% de ácido trifluoroacético (v/v)). A partir desta mistura, 0,3 $\mu \mathrm{L}$ foi aplicado sobre a placa que foi seca a $23^{\circ} \mathrm{C}$ a $25^{\circ} \mathrm{C}$. A calibração da escala de tempo para massa foi realizada usando dois peptídeos padrão (ile7AngllI, Bradicinyn $\mathrm{M}+\mathrm{H}$ 897.531, monoisotopic; e hACTH 18-39, M+H 2465.191, monoisotopic). Os gráficos foram plotados no software Ettan MALDI-ToF Pro versão 2.0. Em seguida, os resultados foram exportados para serem plotados no software mMass - Open Source Massa Tooles Espectrometria.

A atividade antimicrobiana foi realizada com extrato peptídico bruto na concentração de $225 \mathrm{mg} / \mathrm{mL}$. As amostras dos extratos brutos peptídicos foram diluídas em água destilada estéril e, depois, centrifugadas a 917 xg, sendo o sobrenadante obtido utilizado para a realização do teste de atividade antimicrobiana em relação a: Staphylococcus aureus ATCC 6538, Bacillus subtilis ATCC 6633, Enterococcus faecalis ATCC 6057, Pseudomonas aeruginosa ATCC 27853, Klebsiella pneumoniae ATCC 29665 e Escherichia coli ATCC 25922. Estes microrganismos foram selecionados de acordo com a National Committe for Clinical Laboratory Standards (NCCLS, 2003).

Esta atividade foi realizada pelo método de microdiluição em microplacas estéreis de 96 poços (NUNC/Sigma), recomendado pelo NCCLS (2003), em meio de cultura TSB (Caldo Triptona de Soja). A detecção da atividade antimicrobiana foi avaliada por meio da viabilidade celular, utilizando o kit comercial - Resazurin Cell Viability Assay Kit, Biotium, Inc ${ }^{\circledR}$, de acordo com Silva et al. (2012).

A

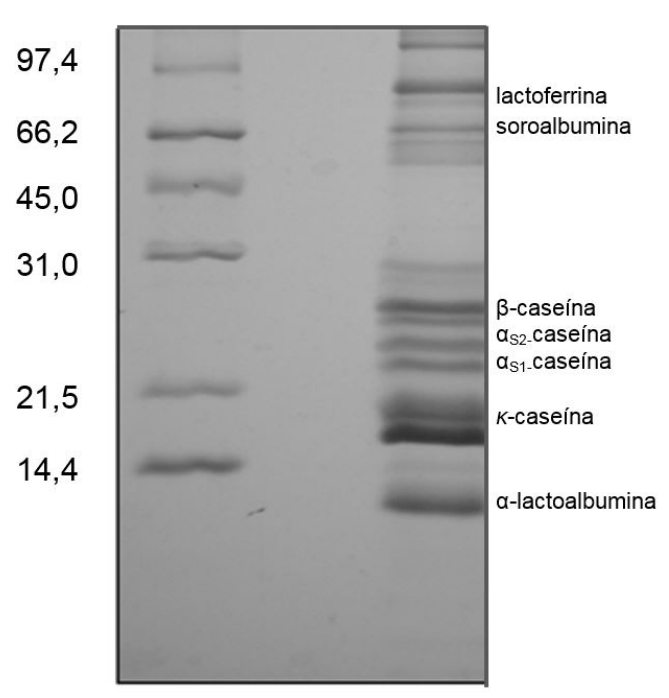

a)

\section{Resultados e discussão}

Depois do procedimento de extração dos peptídeos solúveis de $40 \mathrm{~g}$ de queijo, foram recuperados $86,4 \mathrm{mg}$ de extrato bruto peptídico. De acordo com a quantificação proteica, foi observado que o extrato da primeira coleta apresentou $1,45 \mathrm{mg} / \mathrm{mL}$ e o da segunda coleta, $1,43 \mathrm{mg} / \mathrm{mL}$ em $1 \mathrm{~g}$ do extrato do queijo de Coalho artesanal.

Os resultados do perfil eletroforético dos extratos proteicos brutos extraídos do queijo de Coalho artesanal estão apresentados nas Figuras 1a, b. Foi observada diferença nos perfis entre as coletas, sendo evidenciadas 15 e 12 bandas, na primeira e segunda coleta, respectivamente.

A eletroforese das proteínas extraídas da primeira e segunda coleta de queijo de Coalho apresentou bandas identificadas como: lactoferrina (80 kDa), soroalbumina (66,33 kDa), $\alpha_{\mathrm{s} 1_{1}}$ caseína $(23,61 \mathrm{kDa}), \alpha_{\mathrm{s} 2_{2}}$ caseína (25,23 kDa), $\beta$-caseína (23,98 kDa) e к-caseína (19,02 kDa); e $\alpha$-lactoalbumina (14,2 kDa), já evidenciadas por Park e Jin (1998), quando estudaram a proteólise durante a maturação dos queijos Caciotta e Monterey Jack por SDS-PAGE e análise densitométrica.

A lactoferrina, soroalbumina e $\alpha$-lactoalbumina são proteínas encontradas no soro e referidas como precursoras dos peptídeos bioativos (LÓPEZ-EXPÓSITO; RECIO, 2006). Pappa et al. (2008) analisaram o perfil de proteínas e peptídeos (206 a 6,5 kDa) de extratos solúveis do queijo Teleme produzidos com leite de vaca maturado por 120 dias e também observaram bandas equivalentes a soroalbumina e $\alpha$-lactoalbumina na eletroforese SDS-PAGE monodimensional.

As bandas encontradas neste estudo com peso entre 31 e 21,5 kDa visualizadas no gel de eletroforese são

A

B

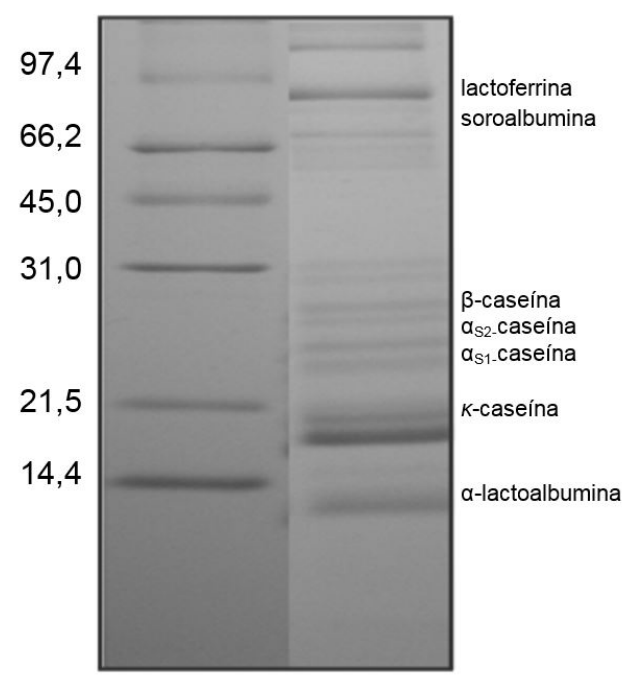

b)

Figura 1. Eletroforese SDS-PAGE do extrato peptídico obtido da (a) $1^{a}$ coleta e (b) $2^{a}$ coleta. (A) Padrão de peso molecular BSA; (B) Principais proteínas identificadas. 
resultantes da hidrólise da caseína pela ação da quimosina, originando os fragmentos de $\alpha_{S_{1}}, \alpha_{S_{2}}, \beta$ e para-k-caseína, que são referidos como as principais proteínas do queijo. Estas também foram visualizadas no trabalho de Egito et al. (2006), ao avaliarem a adulteração do leite de cabra pela adição de leite de vaca, por método eletroforético em gel de poliacrilamida SDS-PAGE,

Vannini et al. (2008) também detectaram a presença de $\beta$ e $\alpha$-caseína ao analisar o perfil eletroforético das proteínas durante o processamento de queijo Pecorino, fabricado com leites submetidos a diferentes pré-tratamentos.

Nos resultados obtidos pela técnica de espectrometria de massas, as relações de massa molecular e carga $(\mathrm{m} / \mathrm{z})$ dos vários peptídeos foram demonstradas de acordo com as intensidades relativas dos picos encontrados nesta amostra de queijo (Figura 2). De um modo geral, a carga dos íons (Z) é +1 e, portanto, a relação $\mathrm{m} / \mathrm{z}$ pode ser comparada com a massa molecular dos peptídeos.

Apenas os peptídeos com m/z < 3500 foram monitorados neste estudo, a fim da compreensão de suas origens. Seus valores $\mathrm{m} / \mathrm{z}$ foram comparados com as massas moleculares de peptídeos relatados e já publicados a partir de diferentes queijos (PAPPA et al., 2008; MIQUEL et al., 2006).

Os peptídeos foram identificados a partir de derivados da fragmentação das caseínas do leite $\left(\alpha_{\mathrm{S} 1}-\mathrm{CN}, \alpha_{\mathrm{S} 2}-\mathrm{CN}\right.$, $\beta$-CN e $\kappa-C N)$. Nas 57 amostras de peptídeos apresentadas pelo espectro de massas (Figura 2), 24 foram identificados (Tabela 1).

Os extratos peptídicos brutos analisados mostraram atividade antimicrobiana na concentração de $225 \mathrm{mg} / \mathrm{mL}$ diante dos microrganismos E. faecalis, B. subtilis, E. coli e $P$. aeruginosa (Tabela 2).

A inibição do crescimento de E. faecalis ATCC 6057 e B. subtilis ATCC 6633 por peptídeos do queijo de Coalho é fator importante na inocuidade do produto, uma vez que algumas cepas de B. subtilis podem produzir toxina termoestável similar à produzida por Bacillus cereus e, após a ingestão, provocar sintomas como vômito e dores abdominais. A inibição do crescimento de E. faecalis impede que estas bactérias assumam importância clínica, podendo desenvolver um processo infeccioso dependendo

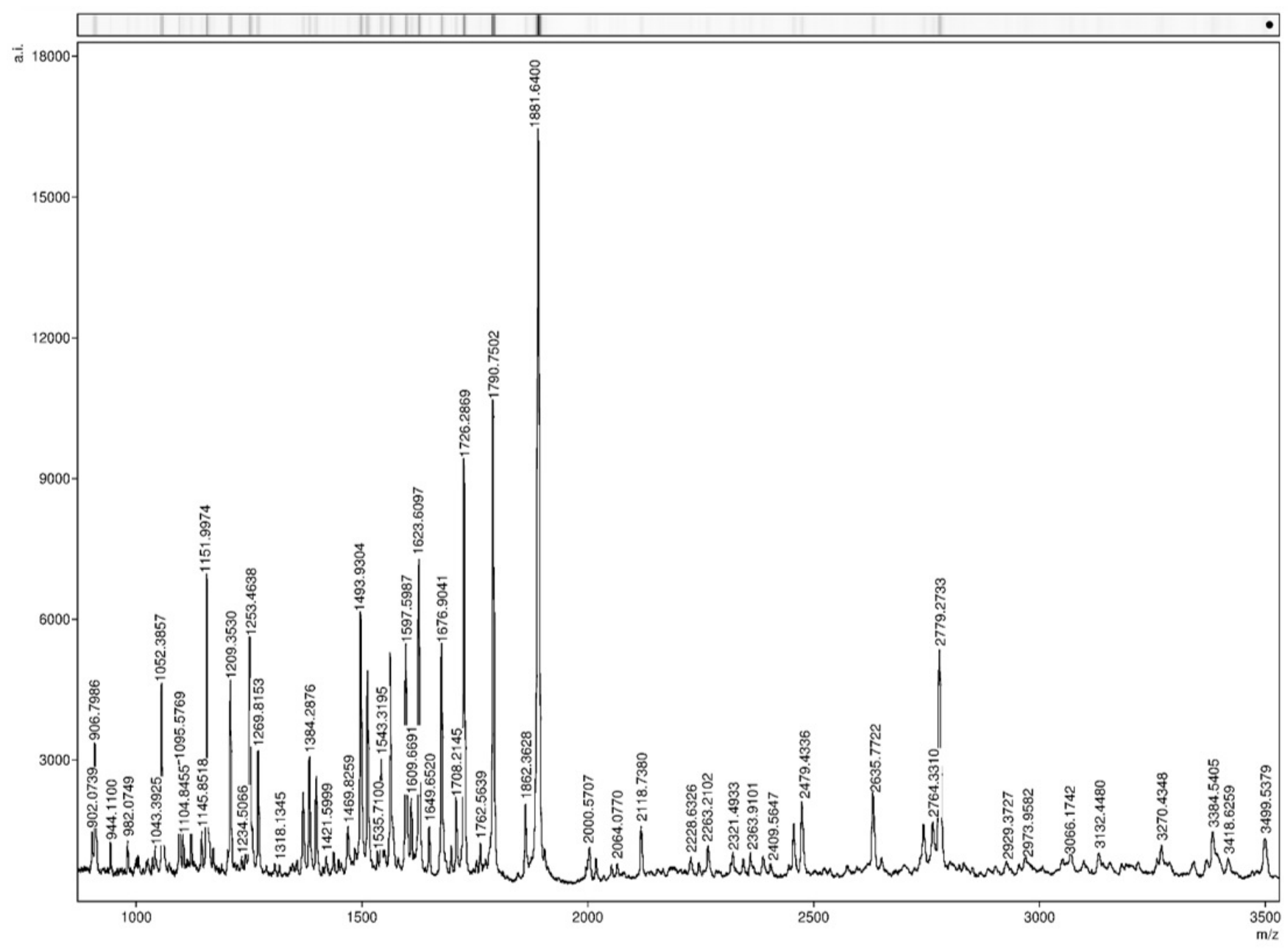

Figura 2. Espectro de massas Maldi-TOF dos peptídeos solúveis do queijo de Venturosa que foram monitorados com $\mathrm{m} / \mathrm{z}<3500$. 
Tabela 1. Lista de peptídeos do queijo de Coalho do Município de Venturosa -PE identificados no espectrômetro de massas MALDI-ToF.

\begin{tabular}{cccccc}
$\begin{array}{c}\text { Massa } \\
(\mathbf{m} / \mathbf{z})\end{array}$ & $\begin{array}{c}\text { Possível fragmento de } \\
\text { caseína }\end{array}$ & $\begin{array}{c}\text { Massa } \\
\mathbf{( m / z )}\end{array}$ & $\begin{array}{c}\text { Possível fragmento de } \\
\text { caseína }\end{array}$ & $\begin{array}{c}\text { Massa } \\
(\mathbf{m} / \mathbf{z})\end{array}$ & $\begin{array}{c}\text { Possível fragmento de } \\
\text { caseína }\end{array}$ \\
805 & $\alpha_{S 1}-C N(f 29-35)$ & 2635 & $\alpha_{S 2}-C N 4 P(f 2-21)$ & 2000 & $\beta-C N 3 P(f 14-28)$ \\
1052 & $\alpha_{S 1}-C N(f 24-32)$ & 2929 & $\alpha_{S 2}-C N 3 P(f 46-70)$ & 2064 & $\beta-C N 1 P(f 33-48)$ \\
1493 & $\alpha_{S 1}-C N(f 24-36)$ & 1151 & $\beta-C N(f 199-209)$ & 2263 & $\beta-C N(f 58-78)$ \\
1568 & $\alpha_{S 1}-C N(f 86-98)$ & 1253 & $\beta-C N(f 58-68)$ & 2343 & $\beta-C N(f 108-127)$ \\
1623 & $\alpha_{S 1}-C N(f 1-14)$ & 1511 & $\beta-C N(f 191-204)$ & 2479 & $\beta-C N(f 133-153)$ \\
1708 & $\alpha_{S 1}-C N(f 24-38)$ & 1676 & $\beta-C N(f 192-206)$ & 3043 & $\beta-C N 3 P(f 1-25)$ \\
2119 & $\alpha_{S 1}-C N(f 1-18)$ & 1790 & $\beta-C N(f 193-208)$ & 999 & $\kappa-C N(f 152-160)$ \\
2363 & $\alpha_{S 1}-C N 41 P(f 73-91)$ & 1881 & $\beta-C N(f 193-209)$ & 1269 & $\kappa-C N(f 51-60)$ \\
\hline
\end{tabular}

Tabela 2. Resultado da avaliação antimicrobiana diante dos extratos peptídicos testados.

\begin{tabular}{|c|c|c|}
\hline \multirow{2}{*}{ Cepas padrão } & \multicolumn{2}{|c|}{ Atividade antimicrobiana ( $225 \mathrm{mg} / \mathrm{mL})$} \\
\hline & Amostra 1 & Amostra 2 \\
\hline Enterococcus faecalis ATCC 6057 & + & + \\
\hline Bacillus subtilis ATCC 6633 & + & + \\
\hline Escherichia coli ATCC 25922 & + & + \\
\hline Pseudomonas aeruginosa ATCC 27853 & + & + \\
\hline Klebsiella pneumoniae ATCC 29665 & - & - \\
\hline Staphylococcus aureus ATCC 6538 & - & - \\
\hline
\end{tabular}

+ = Inibição da cepa patogênica; - = não houve inibição da cepa patogênica.

do estado imunológico do hospedeiro (HERNÁNDEZLEDESMA et al., 2014).

De acordo com a literatura (PAPPA et al., 2008; MIQUEL et al., 2006), entre os peptídeos identificados na Tabela 1, muitos apresentam atividade antimicrobiana na presença de bactérias do tipo Gram positivas e Gram negativas, concordando com os nossos resultados.

$\mathrm{Na}$ eletroforese (Figura 1), foi encontrada a lactoferrina que possui importância na inibição de um grande espectro de microrganismos. A fração da $\alpha$-lactoglobulina também possui atividade antimicrobiana diante de bactérias como E. coli (BERLUTTI et al., 2011; PAN et al., 2007).

O espectro de massas apresentou fragmentos conhecidos por possuírem atividade antimicrobiana semelhantes a Isracidina, que é um peptídeo derivado da $\alpha_{\mathrm{s} 1}-\mathrm{CN}$ tratada com quimosina, e o fragmento $\mathrm{N}$-terminal desta proteína (f1-23) possui atividade antibacteriana diante de bactérias Gram positivas (LÓPEZ-EXPÓSITO; RECIO, 2006).

Mccann et al. (2006) isolaram e identificaram um novo peptídeo, que corresponde ao resíduo (f99-109) da $\alpha_{s 1}$-caseína de leite bovino. Esse peptídeo também apresentou atividade antimicrobiana diante de bactérias Gram positivas como B. subtilis e Gram negativas como E. coli, concordando com a atividade antimicrobiana apresentada neste trabalho.

Além dos peptídeos citados acima, encontrados pela literatura, outros fragmentos peptídicos antimicrobianos (f181-207), (f175-207) e (f164-207) derivados da $\alpha_{\mathrm{s} 2}$-caseína foram identificados a partir da digestão do caseinato de sódio por quimosina, e apresentaram inibição de crescimento de microrganismos Gram positivos e negativos (LÓPEZ-EXPÓSITO; RECIO, 2006).

O peptídeo derivado da $\kappa$-caseína por meio da digestão com tripsina é chamado de k-casecidina e corresponde ao fragmento (f17-21). A k-casecidina pode inibir o crescimento de algumas bactérias patogênicas como E. coli (LÓPEZ-EXPÓSITO; RECIO, 2006).

Tendo em vista os resultados aqui apresentados, os valores do peso inicial do queijo utilizado na extração dos peptídeos, o grau de recuperação dos peptídeos solúveis em água e os resultados da dosagem proteica realizada após a extração dos peptídeos solúveis em água, foi calculado que a ingestão diária de $5 \mathrm{~g}$ do queijo de Coalho artesanal da unidade de processamento do Município de Venturosa - PE seria indicada para obter a quantidade de peptídeos com atividade antimicrobiana diante das bactérias patogênicas avaliadas neste estudo. Entretanto, não foi levada em consideração neste cálculo, a perda pelo processo de digestão. Estes peptídeos são interessantes no produto como agentes de controle de contaminação microbiana, assim como para a manutenção da saúde do consumidor.

\section{Conclusões}

O grande número de proteínas e peptídeos encontrados e identificados no extrato aquoso do queijo de Coalho apresentou potencial em aplicações biológicas 
e biotecnológicas pela confirmação da atividade antimicrobiana. A confirmação científica de bioatividade encontrada nos peptídeos extraídos do queijo de Coalho artesanal é importante para a valorização do produto, além de garantir maior segurança para o consumidor. Sendo assim, pode-se indicar o caráter funcional do queijo de Coalho.

\section{Agradecimentos}

Ao projeto aprovado de número 557665/2006-4 pelo Conselho Nacional de Desenvolvimento Científico e Tecnológico (CNPq).

\section{Referências}

ALMEIDA JÚNIOR, W. L. G.; FERRARI, I. S.; SOUZA, J. V.; SILVA, C. D. A.; COSTA, M. M.; DIAS, F. S. Characterization and evaluation of lactic acid bacteria isolated from goat milk. Food Control, London, v. 53, p. 96-103, 2015. http://dx.doi. org/10.1016/j.foodcont.2015.01.013.

BERLUTTI, F.; PANTANELLA, F.; NATALIZI, T.; FRIONI, A.; PAESANO, R.; POLIMENI, A.; VALENTI, P. Antiviral properties of lactoferrin. A natural immunity molecule. Molecules, Basel, v. 16, n. 8, p. 6992-7018, 2011. PMid:21847071. http://dx.doi. org/10.3390/molecules16086992.

EGITO, A. S.; ROSINHA, G. M. S.; LAGUNA, L. E.; MICLO, L.; GIRARDET, J. M.; GAILLARD, J. L. Método eletroforético rápido para a detecção da adulteração do leite caprino com leite bovino. Arquivo Brasileiro de Medicina Veterinária e Zootecnia, Belo Horizonte, v. 58, n. 5, p. 932-939, 2006. http://dx.doi.org/10.1590/ S0102-09352006000500032.

HERNÁNDEZ-LEDESMA, B.; GARCÍA-NEBOT, M. J.; FERNÁNDEZTOMÉ, S.; AMIGO, L.; RECIO, I. Dairy protein hydrolysates: peptides for health benefits. International Dairy Journal, Barking, v. 38, p. 82-100, 2014

LIRA, B. T. F.; BEZERRA, V. S.; SILVA, F. O.; DIAS, G. M. P.; LIMA FILHO, J. L.; PORTO, T. S.; PORTO, A. L. F. Avaliação de variáveis que influenciam a hidrólise enzimática da caseína do leite de cabra moxotó. Pesquisa Agropecuária Brasileira, Brasília, v. 45, n. 9, p. 1036-1043, 2010. http://dx.doi.org/10.1590/S0100204X2010000900014.

LÓPEZ-EXPÓSITO, I.; RECIO, I. Antibacterial activity of peptides and folding variants from milk proteins. International Dairy Journal, Barking, v. 16, n. 11, p. 1294-1305, 2006. http://dx.doi. org/10.1016/j.idairyj.2006.06.002.

LOWRY, O. H.; ROSEBROUGH, N. J.; FARR, A. L.; RANDALL, R. J. Protein measurement with the Folin phenol reagent. The Journal of Biological Chemistry, Baltimore, v. 193, n. 1, p. 265-275, 1951. PMid:14907713.

MCCANN, K. B.; SHIELL, B. J.; MICHALSKI, W. P.; LEE, A.; WAN, J.; ROGINSKI, H.; COVENTRY, M. J. Isolation and characterisation of a novel antibacterial peptide from bovine s1-casein. International Dairy Journal, Barking, v. 16, n. 4, p. 316-323, 2006. http://dx.doi.org/10.1016/j.idairyj.2005.05.005.

MILLS, S.; ROSS, R. P.; HILL, C.; FITZGERALD, G. F.; STANTON, C. Milk intelligence: mining milk for bioactive substances associated with human health. International Dairy Journal, Barking, v. 21, n. 6, p. 377-401, 2011. http://dx.doi.org/10.1016/j. idairyj.2010.12.011

MIQUEL, E.; GÓMEZ, A. J.; ALEGRÍA, A.; BARBERÁ, R.; FARRÉ, R.; RECIO, I. Identification of casein phosphopeptides after simulated gastrointestinal digestion by tandem mass spectrometry. European Food Research and Technology, New York, v. 222, n. 1-2, p. 48-53, 2006. http://dx.doi.org/10.1007/s00217-005-0023-0.

NATIONAL COMMITTE FOR CLINICAL LABORATORY STANDARDS - NCCLS. Methods for dilution antimicrobial susceptibility tests for bacteria that grow aerobically. Pennsylvania: NCCLS, 2003. p. 1887-1898. NCCLS document M7-A6.

PAN, Y.; SHIELL, B.; WAN, J.; COVENTRY, M. J.; ROGINSKI, H.; LEE, A.; MICHALSKI, W. P. The molecular characterisation and antimicrobial activity of amidated bovine lactoferrin. International Dairy Journal, Barking, v. 17, p. 606-616, 2007.

PAPPA, E. C.; ROBERTSON, J. A.; RIGBY, N. M.; MELLON, F.; KANDARAKIS, I.; MILLS, E. N. C. Application of proteomic techniques to protein and peptide profiling of Teleme Cheese made from different types of milk. International Dairy Journal, Barking, v. 18, n. 6, p. 605-614, 2008. http://dx.doi.org/10.1016/j. idairyj.2007.11.020.

PAQUEREAU, B.; MACHADO, G.; CARVALHO, S. A produção do leite e do queijo se torna cultura. In: PAQUEREAU, B.; MACHADO, G.; CARVALHO, S. O queijo de coalho em Pernambuco: histórias e memórias. Garanhuns: E. dos Autores, 2016. p. 20-27.

PARK, Y. W.; JIN, Y. K. Proteolytic patterns of Caciotta and Monterey Jack hard goat milk cheeses as evaluated by SDS-PAGE and densitometric analyses. Small Ruminant Research, Amsterdam, v. 28 , n. 3, p. 263-272, 1998. http://dx.doi.org/10.1016/S09214488(97)00092-8.

QUEIROGA, R. C. R. E.; SANTOS, B. M.; GOMES, A. M. P.; MONTEIRO, M. J.; TEIXEIRA, S. M.; SOUZA, E. L.; PEREIRA, C. J. D.; PINTADO, M. M. E. Nutritional, textural and sensory properties of Coalho cheese made of goats', cows' milk and their mixture. LWT - Food Science and Technology, Campinas, v. 50, p. $538-544,2013$.

SILVA, R. A.; LIMA, M. S. F.; VIANA, J. B. M.; BEZERRA, V. S.; PIMENTEL, M. C. B.; PORTO, A. L. F.; CAVALCANTI, M. T. H.; LIMA FILHO, J. L. Can artisanal "Coalho" cheese from Northeastern Brazil be used as a functional food? Food Chemistry, London, v. 35, n. 3, p. 1533-1538, 2012. PMid:22953890. http://dx.doi. org/10.1016/j.foodchem.2012.06.058.

VANNINI, L.; PATRIGNANI, F.; IUCCI, L.; NDAGIJIMANA, M.; VALLICELLI, M.; LANCIOTTI, R.; GUERZONI, M. Effect of a 
Queijo de coalho artesanal: fonte alternativa de peptídeos antimicrobianos

Lima, M. S. F. et al.

pre-treatment of milk with high pressure homogenization on yield as well as on microbiological, lipolytic and proteolytic patterns of "Pecorino" cheese. International Journal of Food Microbiology, Amsterdam, v. 128, n. 2, p. 329-335, 2008. PMid:18973961. http://dx.doi.org/10.1016/j.ijfoodmicro.2008.09.018.
ZAFFARI, C. B.; MELLO, J. F.; COSTA, M. Qualidade bacteriológica de queijos artesanais comercializados em estradas do litoral norte do Rio Grande do Sul, Brasil. Ciência Rural, Santa Maria, v. 37, n. 3, p. 862-867, 2007. http://dx.doi.org/10.1590/S010384782007000300040 . 